\title{
The Shear Strength and Dilatancy Behavior of Wheat Stored in Silos
}

\author{
Changnv Zeng ${ }^{1}$ and Yuke Wang $\mathbb{D}^{2}$ \\ ${ }^{1}$ College of Civil Engineering and Architecture, Henan University of Technology, Zhengzhou, 450001, China \\ ${ }^{2}$ College of Water Conservancy Science and Engineering, Zhengzhou University, Zhengzhou, 450001, China
}

Correspondence should be addressed to Yuke Wang; ykewang@163.com

Received 25 May 2019; Accepted 9 July 2019; Published 22 July 2019

Academic Editor: Marcin Mrugalski

Copyright (C) 2019 Changnv Zeng and Yuke Wang. This is an open access article distributed under the Creative Commons Attribution License, which permits unrestricted use, distribution, and reproduction in any medium, provided the original work is properly cited.

\begin{abstract}
This paper focuses on the shear and dilatancy behavior of wheat stored in silos with various densities and normal stresses. The goal is to find a quantitative relationship modeling the peak friction angle and maximum dilatancy angle of wheat stored in silos. A total of 48 direct shear tests were carried out to research the evolution of shear and dilatancy of stored wheat in silos. It is revealed that strength of wheat in bulk attributes to the combination of frictional and dilatant during shearing, in particular attributing to its elliptic shape. An increase in relative density enhances the peak friction angle as well as the dilation. The relationships between relative density, peak friction angle, and dilatancy angle were presented based on the tests data and Bolton's theory. Then an advanced model is developed to evaluate the peak shear behavior of wheat stored in silos considering the dilatancy of the stored wheat. It is a practical method to predict the strength and dilatancy behavior of wheat stored in silos.
\end{abstract}

\section{Introduction}

Grain silos are special structures in industry for storing agriculture materials, which are widely used in the whole world [1]. The failure of silos may not only cause the loss of stored material itself, but also sometimes cause an explosion. Wheat is one of the important raw materials, which provides approximately twenty-one percent of the world's food [2]. Because of large amount of wheat production and large population in China to serve, most of the wheat in China is stored in silos for three to five years. The long-term storage system is very different from those in other countries [3]. Therefore, the storage of wheat in silos is of great concern to the government, engineers, and scientists. The mechanical properties of the stored materials are primarily important to design in the silos [4].

Janssen' theory, found in 1895, is still the basis of most internal standards to gain the loads applied on silos [5-10]. It is simple to obtain the loads with some common material properties of the internal friction of stored materials, friction coefficient of agriculture grain to wall, etc. These common properties of grain such as frictional angle, bulk density, and friction angle between concrete and steel have been widely investigated by many researchers [11-16]. However, it is found that the "real silo loads" measuring from silos are more complex than those obtained by Janssen's theory, which still provides new uncertainties in the design [17]. The stored materials are undergoing various forces, such as gravity loading, friction with the silo walls, which change with depth during silo filling, and discharging [18-25]. For example, the dilatancy phenomenon usually occurred during silo discharging. As a result, the numerical methods are usually adopted to accurately simulate silo loads during the storage conditions. It is necessary to investigate the stressstrain model including friction and dilatancy behavior for agricultural materials at different conditions in silos.

Direct shear tests are widely used to investigate the mechanical properties of materials, especially for soils [2630]. However, for agriculture material the mechanical properties are still poorly understood [5], especially for the large amount and long-term stored wheat in China. In this work, the strength and dilatancy behavior of wheat is investigated using direct shear tests under different normal stresses and relative densities. The stress-dilatancy model was built based 
TABLE 1: Physical properties of wheat.

\begin{tabular}{lccccc}
\hline Sample & $\begin{array}{c}\text { Maximum grain } \\
\text { size }(\mathrm{mm})\end{array}$ & $\begin{array}{c}\mathrm{D}_{60} \\
(\mathrm{~mm})\end{array}$ & $\begin{array}{c}\mathrm{D}_{10} \\
(\mathrm{~mm})\end{array}$ & $\begin{array}{c}\text { Coefficient of } \\
\text { uniformity, } \mathrm{C}_{\mathrm{u}}\end{array}$ & ${\text { Specific gravity, } \mathrm{G}_{\mathrm{s}}}$ \\
\hline Wheat & 5 & 4.12 & 3.36 & 1.23 & 1.34 \\
\hline
\end{tabular}

TABLE 2: Properties for shear tests of wheat.

\begin{tabular}{lcccc}
\hline Sample & $e_{\max }$ & $e_{\min }$ & Initial void ratio values used & $\begin{array}{c}\text { Normal stress } \\
(\mathrm{kPa})\end{array}$ \\
\hline Wheat & 0.668 & 0.450 & $0.487,0.491,0.496,0.506,0.510,0.515,0.523,0.532$, & $50,100,150$ \\
\hline
\end{tabular}

on the relationship of friction and dilatancy angle. The effects of relative densities and normal stresses were also examined.

\section{Experimental Procedure and Materials}

2.1. Materials. The wheat samples used in this project were uniformly graded winter wheat, grown in Henan Province of China. Different parameters were used to describe the wheat, including:

(1) Particle Shape and Particle Size Distribution. The particle shapes were quantified by Zingg index to measure the particle shape. The length of major axis (L), minor axis (B), and its thickness (T) are used to describe the particle shape shown in Figure 2. The average Zingg index is 1.62, which indicates the rod-shaped particle for wheat. The grain size distribution curve was shown in Figure 3, and the coefficient of uniformity for wheat was obtained. It showed the wheat was very uniform and poorly grade. The main properties of wheat used were summarized in Table 1.

(2) Void Ratio. The granular mass is commonly considered to be consisted of a network of solid particles, enclosing voids of varying sizes. The void ratio of samples is described as

$$
e=\frac{\rho_{s}-\rho}{\rho}=\frac{\rho_{s}}{\rho}-1
$$

where $\rho_{s}$ is density of wheat particle with the same quantitative value of the specific gravity $G_{s}=1.34, \rho$ is the density of wheat mass, and $e$ is the void ratio. In this paper, the values of $e_{\max }$ and $e_{\min }$ are 0.668 and 0.450 for wheat, respectively, according to SL237-1999 [31]. The detailed properties of void ratio were listed in Table 2 . The density of sample can be evaluated by comparing with the value of $e_{\max }$ and $e_{\text {min }}$. Here $e_{\max }$ represents the state of void ratio at loosest condition, which is achieved by quickly inverting the wheat in a container. And $e_{\text {min }}$ is measured by vibration without causing wheat particle crushing.

Specimens with different void ratio were prepared by pouring a specified mass of dry wheat into the shear box, by deposition with a spoon for loose samples, in five lifts each tamped by using a steel rammer for dense samples without destroying grain particle, until the required void ratio was achieved for each layer.
(3) Moisture Content. The moisture content was obtained from wheat flour with oven drying method. Some representative crushing wheat flour sample of $10 \mathrm{~g}$ was placed in a dish, which was dried at $105^{\circ} \mathrm{C}$ in an oven for at least 3 hours. The moisture content of wheat particle when crushing into flour was $10.6 \%$ by dry basis.

2.2. Testing Apparatus and Procedure. The developed shear box with circular cross section was $100 \mathrm{~mm}$ in diameter and $100 \mathrm{~mm}$ in depth as shown in Figure 1. The shear cell diameter should be at least 20 times the maximum particle size and not less than 40 times the mean particle size, as recommended by Eurocode 1 Part 4 . In the study, the values of the mean particle size and the mean particle size are $5 \mathrm{~mm}$ and 4.02 $\mathrm{mm}$, according to the particle distribution curve, respectively, which are partly satisfying the size of cell box in Eurocode 1. However, the size of shear box is not very accurate with the requirement when it exceeds 40 times mean particle size. Most of the shear boxes in the literatures are less than 100 $\mathrm{mm}$ because of the limitation of the shear device used. In addition, the results in a large box of $143 \mathrm{~mm}$, considering the ratio of $5 \%$ between sample size and grain size, are similar to those by the authors [21]. Regardless, the test results provided by these shear devices show considerable parameters for the agricultures materials.

As shown in Figure 1, the upper part of the shear box is restrained, while the lower part is controlled by a motor to apply the horizontal shear load with displacement-controlled mode. The vertical normal load is imposed by the upper platen, which is fixed with the upper part of shear box. The opening size of the two halves of shear box is $2 \mathrm{~mm}$, which is corresponding to the requirement according to Shibuya et al. [32]. During the tests the loads and displacements at axial and horizontal directions were recorded automatically by a computer-controlled data collection system.

Test samples were prepared by dry pouring method with 10 layers to obtain specified densities. For dense sample it may be vibrated or compaction without grain crushing. In this study, the influences of void ratio and normal stress on stress-dilatancy behavior were examined. The values of void ratio ranged from 0.487 to 0.668 with normal stress of $50 \mathrm{kPa}$, $100 \mathrm{kPa}$, and $150 \mathrm{kPa}$, which usually existed for stored wheat in situ silos. The shearing velocities are set as $2.4 \mathrm{~mm} / \mathrm{min}$ until the horizontal displacement reaches more than $20 \mathrm{~mm}$. 


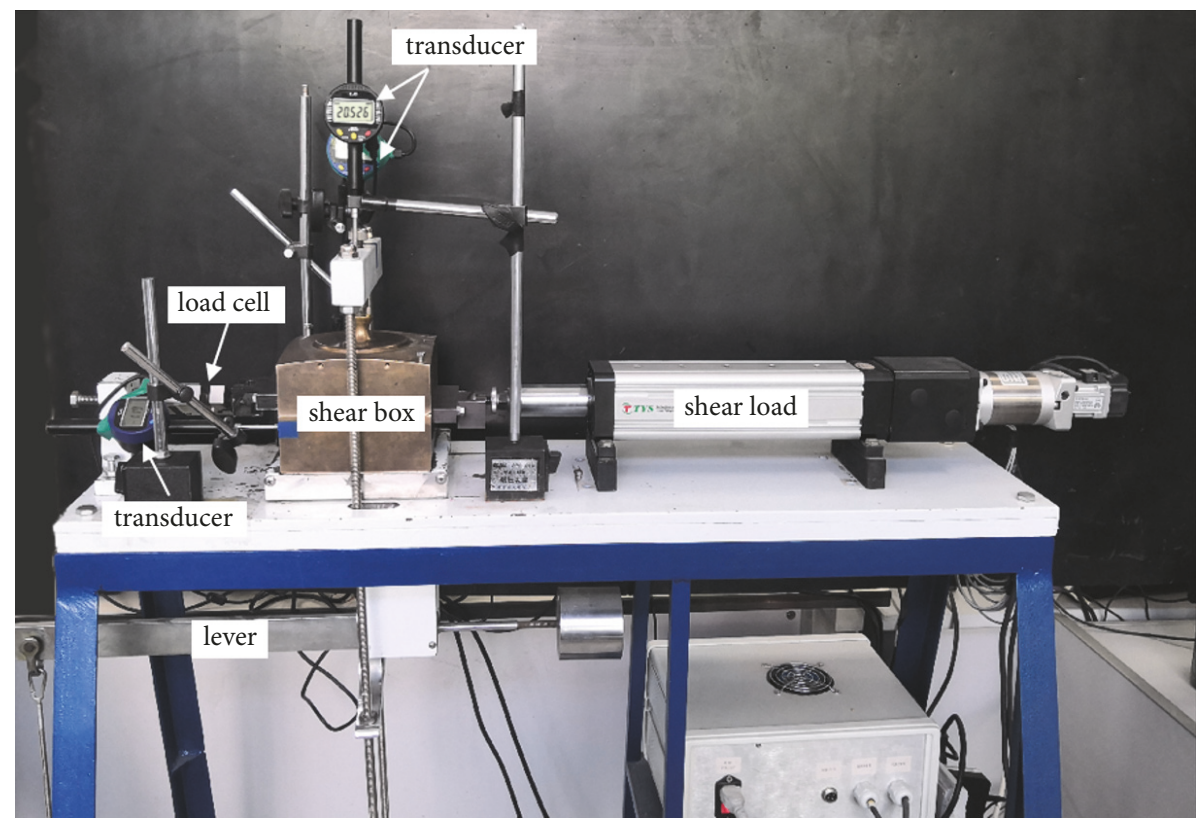

FIgURE 1: The direct shear box apparatus.
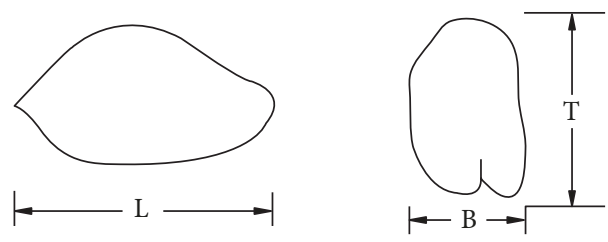

Figure 2: Size of wheat grain.

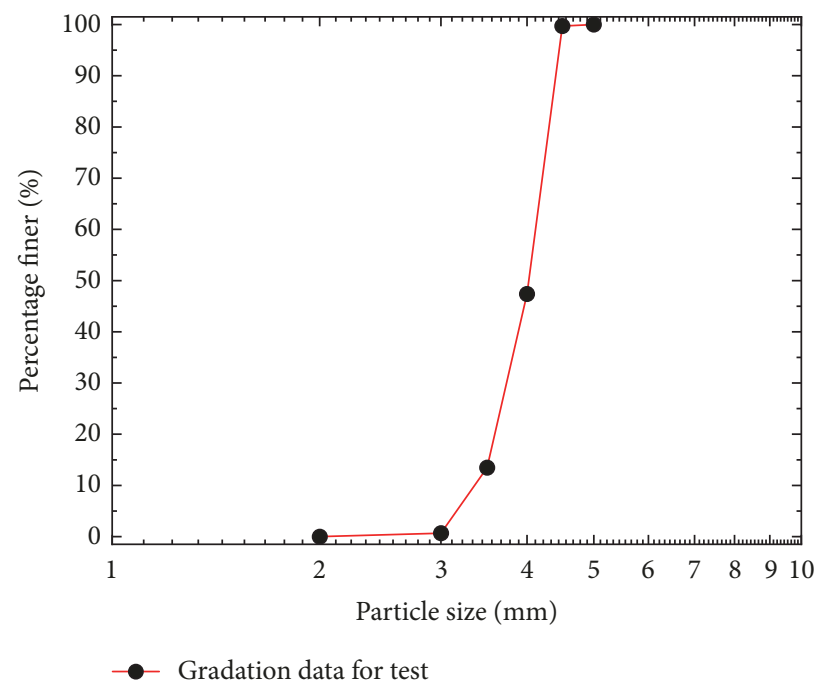

FIgURE 3: Grain size distribution of wheat used.

\section{Experimental Results}

3.1. Stress-Strain Behavior and Volumetric Response. A series of direct shear tests were carried out with a consideration of different levels of void ratios and normal stresses. The initial void ratio of specimen ranged from 0.487 to 0.668 including loose and dense specimens. The typical curves of three void ratios are shown in Figures 4-6 with normal stresses ranged from $50 \mathrm{kPa}$ to $150 \mathrm{kPa}$. The stress-strain evolution was plotted in terms of ratio between shear strength and normal stress $\mathrm{R}=\tau / \sigma_{v}^{\prime}$ and horizontal displacement $u$. The volumetric response was characterized as vertical normal displacement and horizontal shear displacement. For the dense wheat sample with relative density $D_{r}=83 \%$ at normal stress of $50 \mathrm{kPa}, \tau / \sigma_{v}^{\prime}$ increases with the increase of horizontal displacement $u$, while it reached the peak value at about $u=5 \mathrm{~mm}$. After that the stress ratio $\tau / \sigma_{v}^{\prime}$ keeps constant at a relatively small range until it decreases to a stable state at large horizontal displacement, which is called a critical state. During the shearing process, significant dilative deformation occurs; then a small contraction occurs in the initial stage. The maximum amount of dilation reaches the peak strength state. After the plateau stage of curve in Figure 4, the rate of dilation decreases with continuous shearing and then the critical stage is achieved. With the void ratio increasing, both the peak value of $\tau / \sigma_{v}^{\prime}$ and dilative deformation reduce with the generation of horizontal displacement. Furthermore, dilation nearly vanishes for the loose sample with $e_{0}=0.641$ at $150 \mathrm{kPa}$.

Comparing the responses of wheat at different initial void ratios, the loose sample requires larger horizontal displacement to obtain the peak horizontal shear stress than that of dense sample at the same normal stress. However, the postpeak strain softening of loose sample is gentler than that of dense sample. As expected, the critical state is confirmed using the results as shown in Figures 4-6 for all the test samples. The effect of normal stress on stress-strain response is also examined. As shown in Figures 4-6, at the same initial 


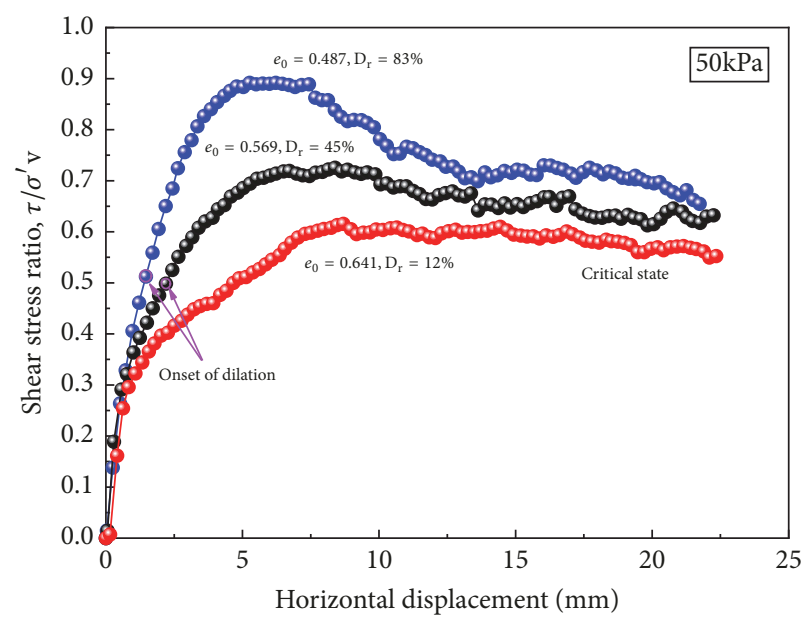

(a)

FIgURE 4: Experimental results of stress-strain response $(50 \mathrm{kPa})$. displacement-horizontal displacement.

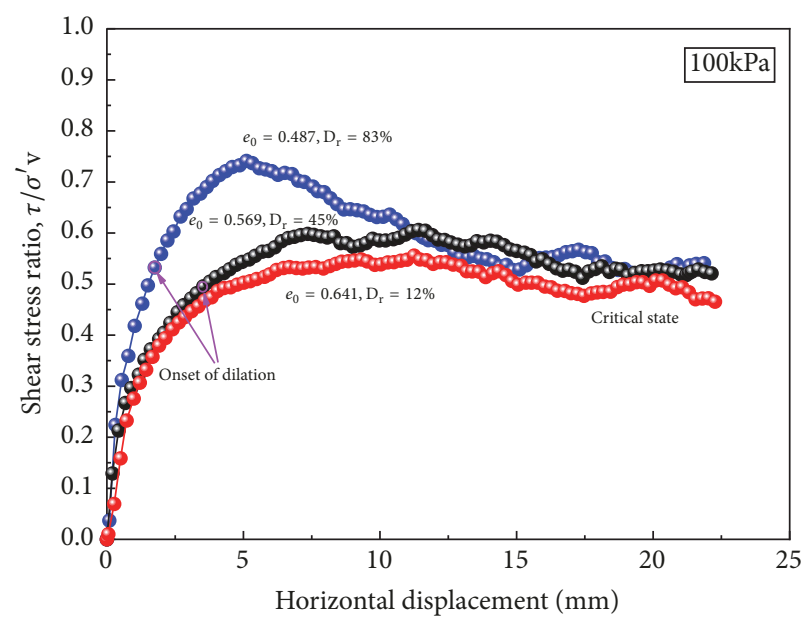

(a)

FIgURE 5: Experimental results of stress-strain response (100 kPa) displacement-horizontal displacement.

void ratio, the final vertical displacement decreases with the increasing normal stress, and this suppresses the dilation. The samples with different void ratio show the same trend.

3.2. Peak Strength Friction Angle. The peak state represents the maximum shear strength of the wheat sample, which was determined when the horizontal shear stress meets its maximum value. The peak direct shear friction angle $\phi_{d s}^{\prime}$ is defined with

$$
\phi_{d s}^{\prime}=\tan ^{-1}\left(\frac{\tau}{\sigma_{v}^{\prime}}\right)
$$

where $\tau$ and $\sigma_{v}^{\prime}$ denote horizontal shear stress and normal stress.

Two methods can be used to obtain the strength friction angle at the peak state, which are interpreted of a single

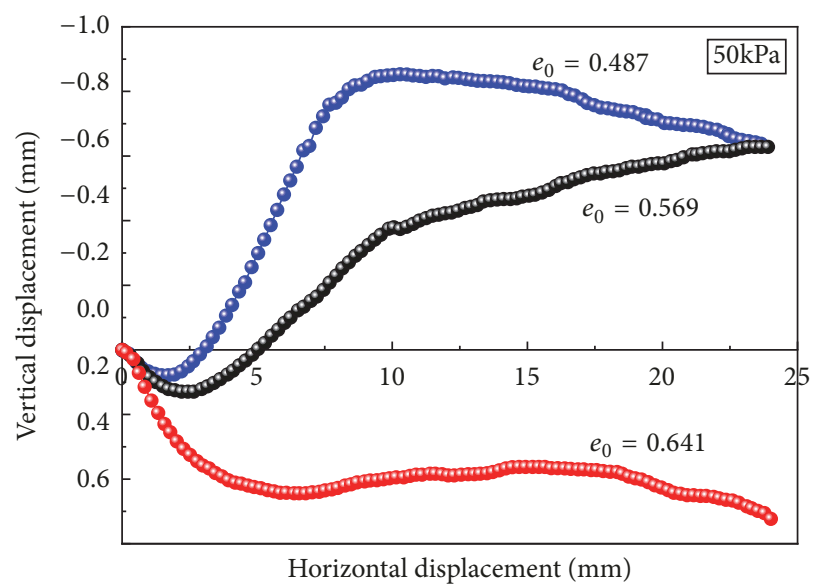

(b)

(a) Shear stress ratio-horizontal displacement curve. (b) Vertical

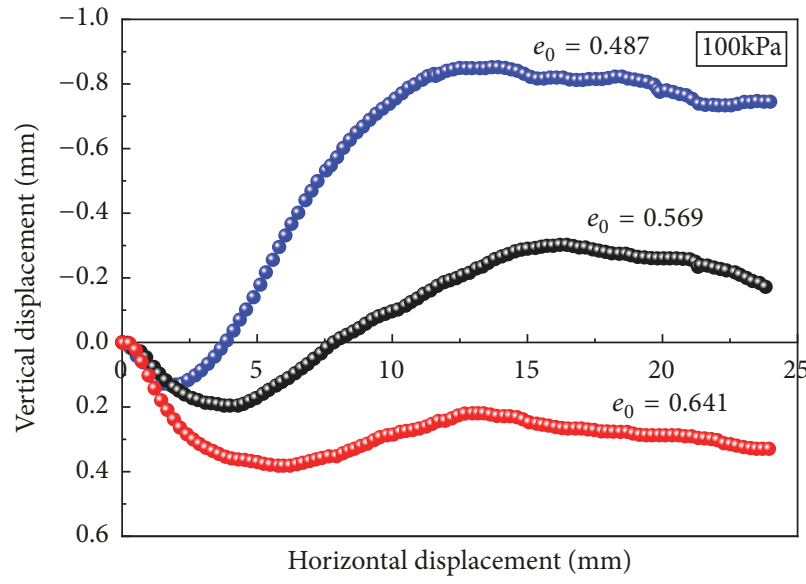

(b)

(a) Shear stress ratio-horizontal displacement curve. (b) Vertical test (first method) or multiple tests (second method). The first method is the direct measurement from shear stress ratio of mobilized shear stress to normal stress at peak state. The results obtained from the first method are shown in Figure 7. It shows that an increase of peak friction angle performs with the increase of relative density. However, the peak friction angle of wheat decreases with the increase of normal stress. Figure 8 shows an example of the second method to obtain the friction angle with multiple tests curves of shear stress versus normal stress. The intercept equals $\tan \varphi$, in which $\varphi$ is also called internal friction angle. It is one of the useful mechanical properties in silo design as recommended by most of silo codes, which is greatly affected by the density of sample. Figure 9 showed the effect of relative density on internal friction angle at peak state strength. A gradual increase occurs with the increase of relative density 


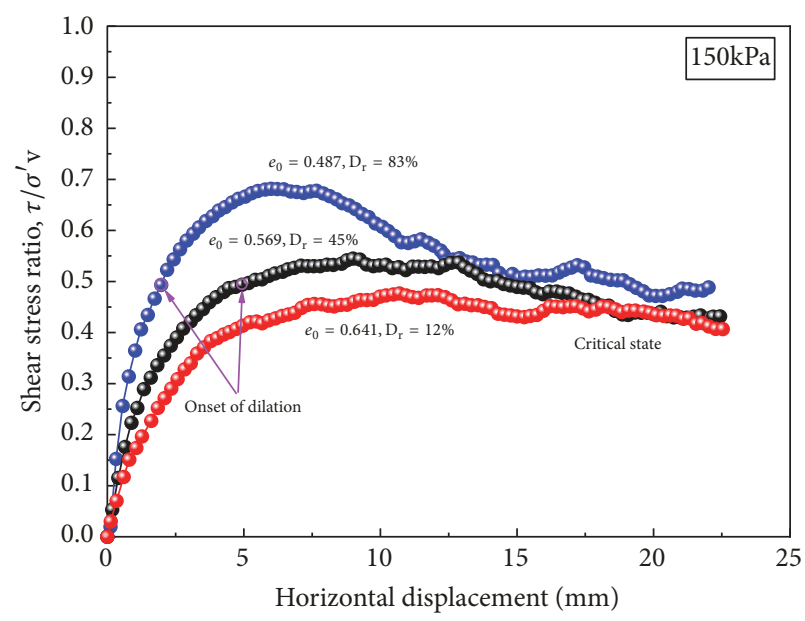

(a) displacement-horizontal displacement.

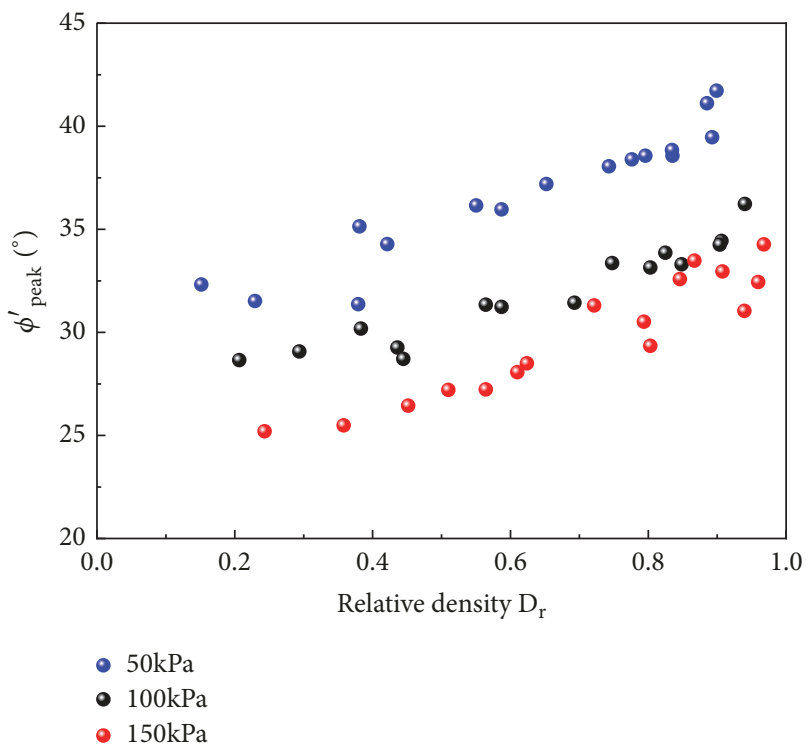

FIGURE 7: Relationships between peak friction and relative density.

of samples, which indicates denser sample exhibits higher internal friction angle and thus higher shear strength.

The shear behavior of wheat was similar to the angular sand, which was also influenced by its angularity particle shape [33]. As is well-known to us all, wheat grain is elliptic shape, which may cause large interparticle locking between the particles when they slide or rotate during shearing. High shear stress occurs to overcome the locking between particles, just before the dilation takes place. Thus, it also implies that the shear resistance is the combined action of particle interlock and dilation. In the initial stage of shearing, the interparticle locking dominates while dilation tends to play prevailing effect after a coupled effect of dilation and interlocking. The plateau curve in Figure 6 describes the consequence of couple effect. More specially, the interlocking

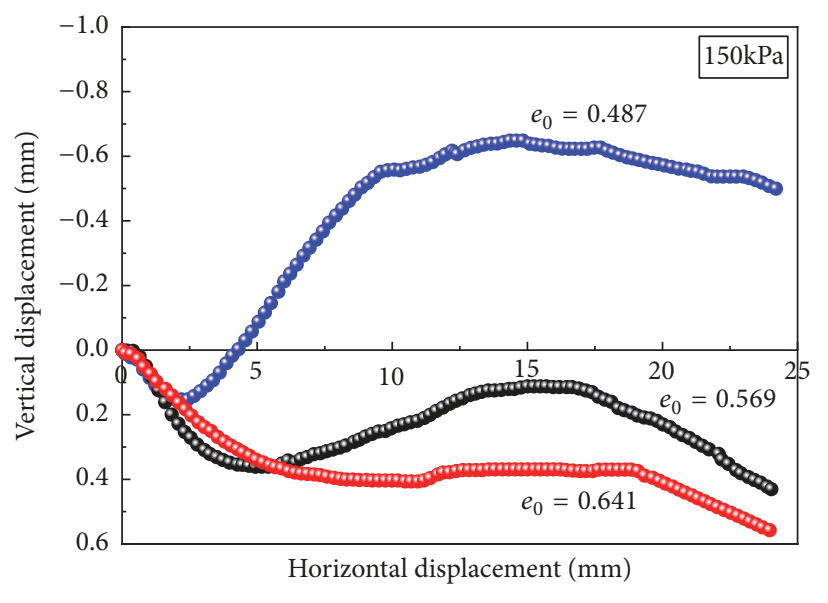

(b)

(a) Shear stress ratio-horizontal displacement curve. (b) Vertical

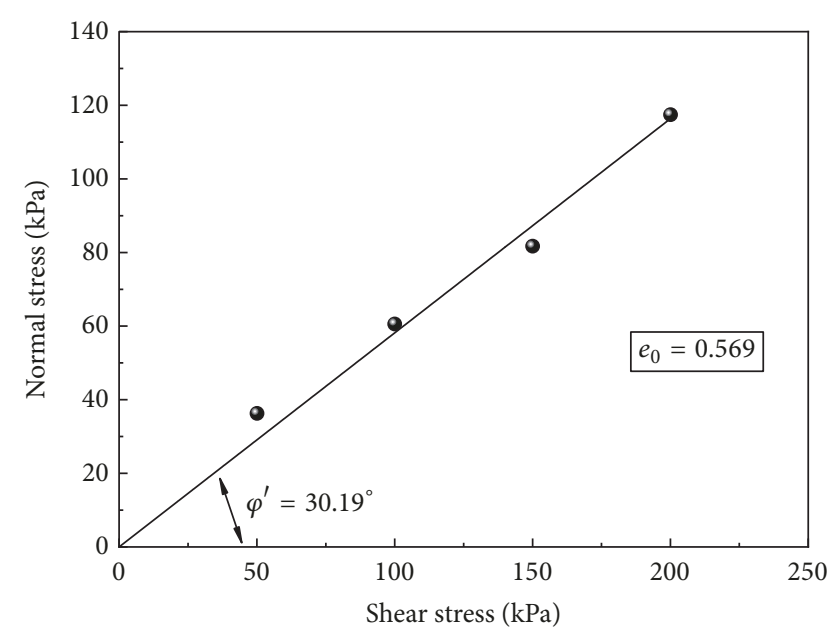

FIGURE 8: Shear stress against normal stress at peak state $\left(e_{0}=\right.$ $0.569)$.

action decreases with the development of horizontal displacement. It is noted that these observations are very similar to those of sands [33-35].

3.3. Critical State Friction Angle $\phi_{c v}^{\prime}$. In this paper the friction angle at critical state is used to represent the minimum shear strength condition during shearing. It is fundamental to describe the shear behavior at constant volume shearing condition with the theory of dilatancy. In this paper, the critical state friction angle is obtained based on the fitted line of $\phi_{\text {peak }}^{\prime}$ against $\psi$ according to Simoni and Houlsby [26]. Here, $\phi_{\text {peak }}^{\prime}$ is the peak friction, while $\psi$ is measured at the point corresponding to peak strength. The intercept of the fitted line is the derived critical friction angle at the point of dilatancy angle $\psi=0$ as shown in Figure 10. At least two tests are needed at various densities for this method, which shows more reliable than that obtained from single test results [26]. 


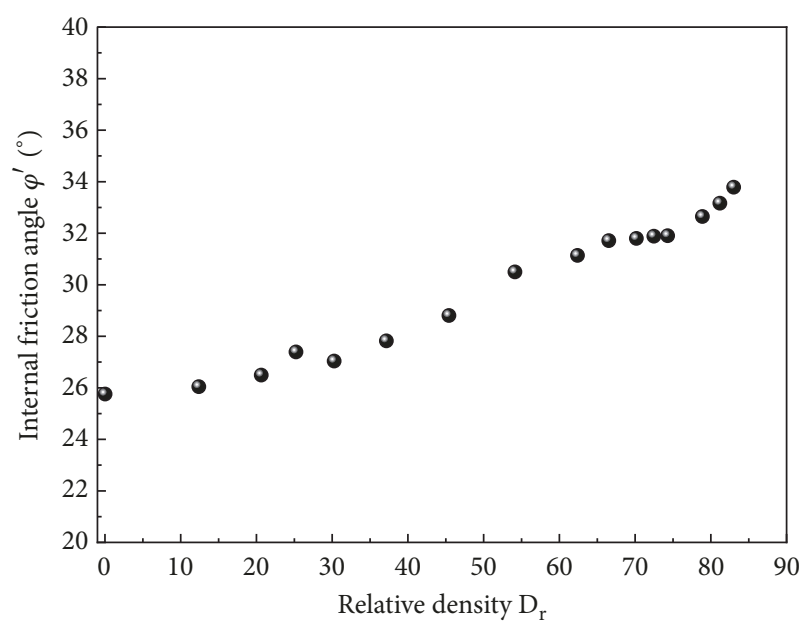

FIGURE 9: Internal friction angles of different relative density at peak state.

The result is also compared with Bolton's dilatancy equation $[36,37]$. In this study, $\phi_{c v}^{\prime}$ is derived from a wide range of densities of wheat direct shear tests. The test results of peak friction $\phi_{\text {peak }}^{\prime}$ and dilatancy angle $\psi$ are regressed as shown in Figure 10. A linear fitted line with the direct shear tests of wheat in bulk is observed. The derived $\phi_{c v}^{\prime}$ value for wheat at different normal stresses shows substantially different values. The $\phi_{c v}$ values are $31.46^{\circ}, 28.19^{\circ}$, and $25.71^{\circ}$ for normal stresses $50 \mathrm{kPa}, 100 \mathrm{kPa}$, and $150 \mathrm{kPa}$, respectively. It can be seen that the critical state friction angle decreases with the increase of imposed normal stress. The observation of derived critical state friction related to the normal stress is probably caused by the effect of deformable wheat particle at large normal stress, which is somewhat similar to that of rockfill materials [38].

\section{Dilatancy Behavior of Wheat}

As showed in Figures 4-6, the vertical displacement and horizontal displacement are also measured as well as the shear strength. In the direct shear stress condition, the rate of dilation of wheat $d v / d u$ is directly calculated by the ratio of vertical displacement $v$ to the horizontal displacement $u$, which is shown in

$$
\tan \psi=\frac{d v}{d u}
$$

The differential value of $d v / d u$ should be smoothing as the measured displacement is obtained at very short interval of time. The successive readings are tested for several time until the appropriate moving average value of three readings $d \mathrm{u} \approx 0.70 \mathrm{~mm}$ is obtained, which shows a limit scatter and sufficient smooth relation between dilation ratio and shear displacement. It is expected that value of $(d v / d u)_{\max }$ is coincident with the value of $\left(\tau / \sigma_{v}^{\prime}\right)_{\max }$. It is also used to calculate the maximum dilation angle $\psi_{\max }$.

A group of test results of maximum dilatancy angles vary with densities and normal stresses, as shown in Figure 11. It is revealed that dilatancy angle increases with an increase

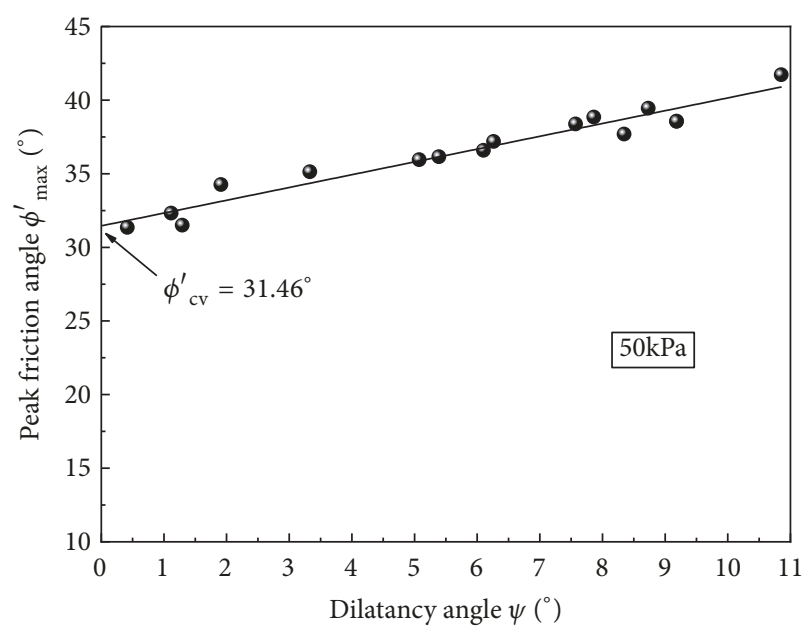

(a)

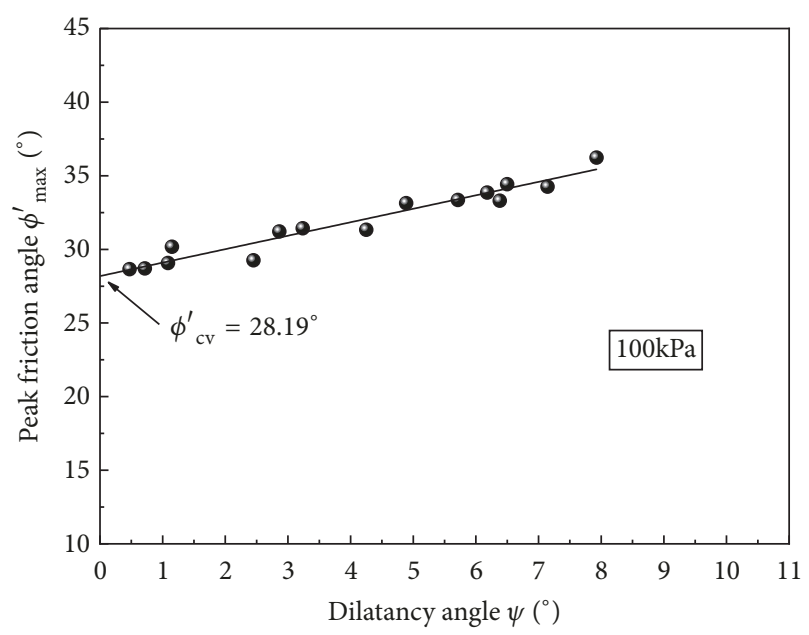

(b)

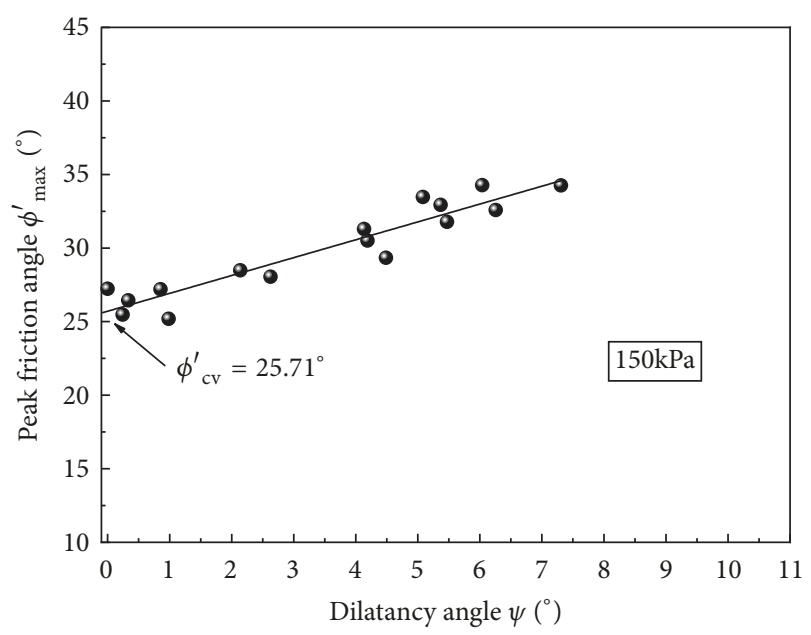

(c)

FIGURE 10: The method used for determination of the critical state friction angle. (a) $50 \mathrm{kPa}$; (b) $100 \mathrm{kPa}$; (c) $150 \mathrm{kPa}$.

of relative density, while it decreases with increasing normal stress. As an example, for specimen with $e_{0}=0.487$, the 


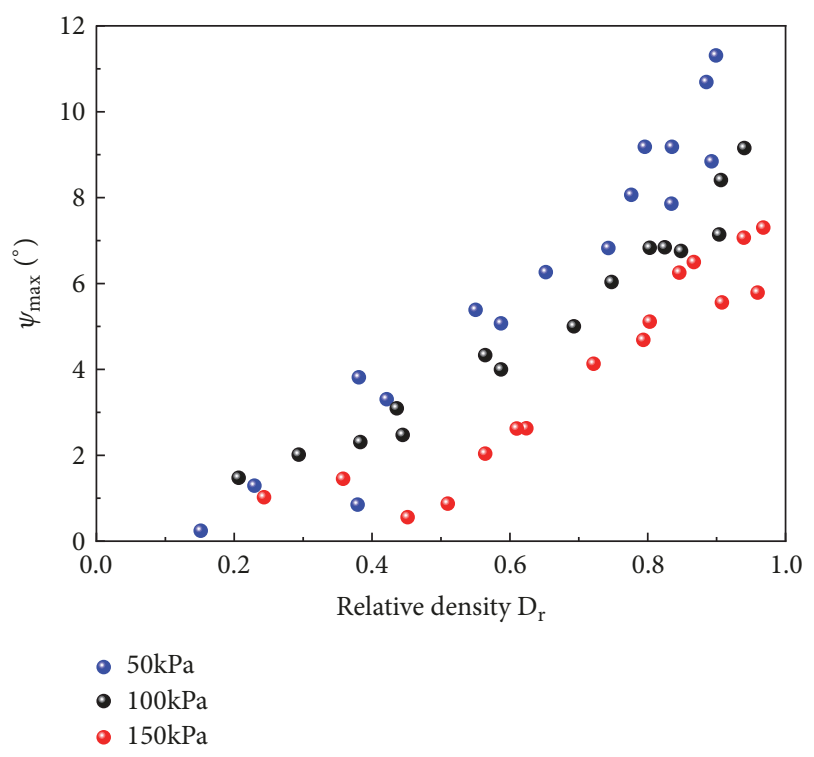

Figure 11: Maximum dilatancy angle versus relative density at different normal stress.

average dilatancy angle of $11.3^{\circ}$, and for $e_{0}=0.668$ that is $2.86^{\circ}$ under imposed normal stress of $50 \mathrm{kPa}$. For the specimen with $e_{0}=0.487$, the dilatancy angles were $11.3^{\circ}$, $10.3^{\circ}$, and $8.3^{\circ}$ under normal stress of $50 \mathrm{kPa}, 100 \mathrm{kPa}$, and $150 \mathrm{kPa}$, respectively. It can be indicated that the dilation may be suppressed with the increase of imposed normal stress. The stress and dilation behavior of wheat in bulk is consistent with those reported results of various sands [26-28].

\section{Discussion}

Bolton $[37,38]$ presented a new empirical equation based on Rowe's theory, which is widely used for various sands shown in

$$
\phi_{\text {peak }, p s}^{\prime}-\phi_{c v, p s}^{\prime}=0.8 \psi_{\max }
$$

In this paper, the framework of Bolton's equation is adopted to interpret the experimental result of direct shear tests of wheat in bulk.

Figure 12 presented the relationship of peak friction angle $\phi_{\text {peak,ds }}^{\prime}$ and the maximum dilation angle $\psi_{\max }$ in direct shear tests. As seen from Figure 12, the test data of wheat in bulk is fitted using (5) for wheat based on Bolton's equation.

$$
\phi_{p e a k, d s}^{\prime}-\phi_{c v, d s}^{\prime}=0.8 \psi_{\max }
$$

From the fitted curve $b=0.85$ for normal stress of $50 \mathrm{kPa}$ is matched.

A linear relationship between $\phi_{\text {peak,ds }}^{\prime}$ and $\psi_{\max }$ is observed in Figure 12 and (5) from experiment investigations. The presentation in (5) is deduced on the framework of Bolton [36, 37], which agrees with (4) by Bolton for the plane strain conditions. As above descriptions, the theory for plane strain conditions proposed by Bolton $[36,37]$ is also suit for the case of direct shear tests, for example, of wheat direct

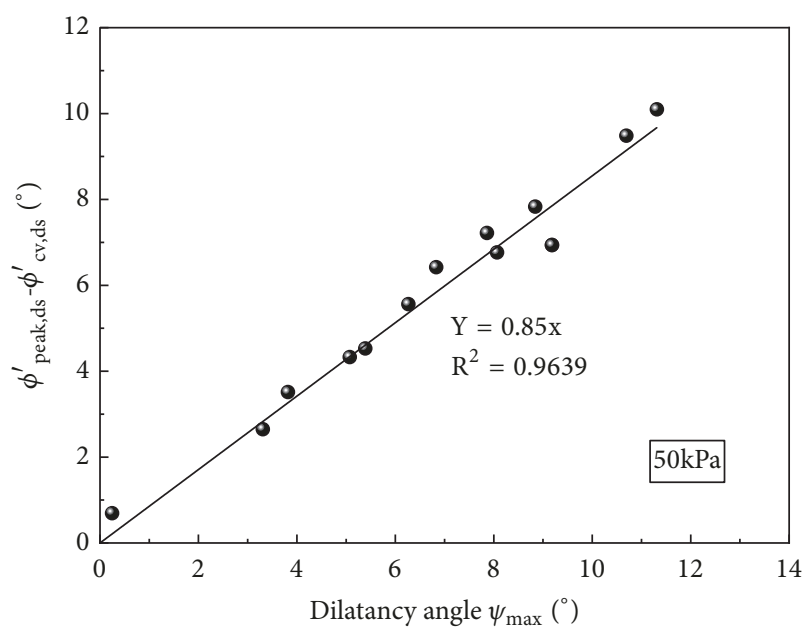

FIGURE 12: Peak friction angle $\phi_{\text {peak,ds }}^{\prime}$ versus maximum dilation angle $\psi_{\text {max }}(50 \mathrm{kPa})$.

shear tests. Thus, the equation can be deduced in terms of the friction angle obtained from direct shear tests. The series of scattered test data of wheat is fitted with the deduced equation according to Bolton's theory.

The influence of density, confining pressure on peak friction angle, was also examined by Bolton [36, 37]. Here, the widely accepted definition of compaction is used in (6), which is named as relative density $D_{\mathrm{r}}$. In this theory, a new index called relative dilatancy index $I_{R}$ is developed, which in turn combines $D_{\mathrm{r}}$ and normal stress with its shear resistance and corresponding peak friction angle.

$$
\begin{aligned}
D_{r} & =\frac{e_{\text {max }}-e}{e_{\text {max }}-e_{\text {min }}} \\
\phi_{\text {peak }, d s}^{\prime}-\phi_{c v, d s}^{\prime} & =5 I_{R} \\
I_{R} & =D_{r}\left(Q-\ln \left(\sigma_{v}^{\prime}\right)\right)-1
\end{aligned}
$$

In this work, the effects of relative density and normal stresses are also examined for wheat in bulk. The typical test results are plotted in Figure 13. The quantitative correlation was showed in (7) and (8), where the parameter $Q$ value is 7.45 to 7.64 with an average value of 7.54 for wheat.

\section{Conclusions}

The shear and dilatancy behavior of wheat stored in silos are presented in this paper. The direct shear tests of wheat are carried out at various levels of densities and normal stresses in order to investigate the influence of relative density and normal stress on shear and dilation behavior of wheat. Both the peak friction angle and internal friction angle increase with the increasing relative density of wheat sample. It is observed that denser sample with higher relative density enhances the dilation by higher dilatancy angle, whereas the dilation is suppressed with increasing normal stress. Based on the framework of Bolton's theory, the relationship between 


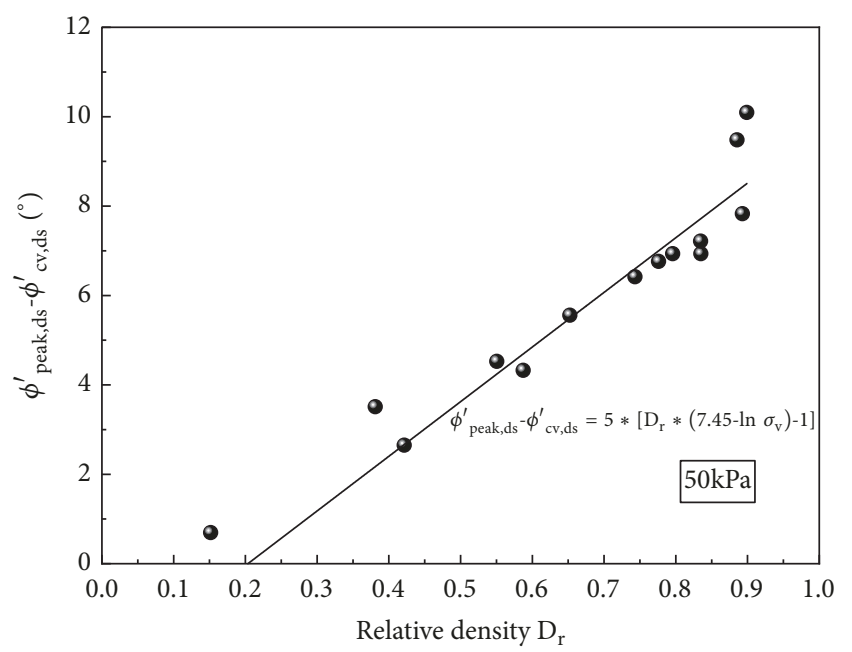

FIGURE 13: Relationship between $\phi_{\text {peak,ds }}^{\prime}-\phi_{c v, d s}^{\prime}$ and relative density $\left(\sigma_{v}^{\prime}=50 \mathrm{kPa}\right)$.

peak friction angle and maximum dilatancy angle is deduced with a consideration of relative density effect.

\section{Data Availability}

The data used to support the findings of this study are available from the corresponding author upon request.

\section{Conflicts of Interest}

The authors declare that they have no conflicts of interest.

\section{Acknowledgments}

This research was substantially supported by Plan for Youth Core Teachers of Henan University of Technology (2015004), Plan for the Key Projects of High Schools of Henan province (19A560009), and Provincial Key Laboratory for Grain and Oil Storage Facility \& Safety, Henan University of Technology (2016KF-B03).

\section{References}

[1] H. Li, Analysis of Steel Silo Structures on Discrete Supports [Ph.D. thesis], The University of Edinburgh, Edinburgh, Scotland, UK, 1994.

[2] R. Ortiz, K. D. Sayre, B. Govaerts et al., "Climate change: can heat beat the heat?" Agriculture, Ecosystems \& Environment, vol. 126, no. 1-2, pp. 46-58, 2008.

[3] X. Li, Z. Cao, Z. Wei, Q. Feng, and J. Wang, "Equilibrium moisture content and sorption isosteric heats of five wheat varieties in China," Journal of Stored Products Research, vol. 47, no. 1, pp. 39-47, 2011.

[4] A. Dogangun, Z. Karaca, A. Durmus, and H. Sezen, "Cause of damage and failures in silo structures," Journal of Performance of Constructed Facilities, vol. 23, no. 2, pp. 65-71, 2009.

[5] F. Ayuga, P. Aguado, E. Gallego, and Á. Ramírez, "New steps towards the knowledge of silos behaviour," International Agrophysics, vol. 19, no. 1, pp. 7-17, 2005.
[6] "EN 1991-4, Eurocode 1 - Actions on structures - Part 4," Silos and Tanks. European Committee for Standardization, Brussels, 2006.

[7] "ACI 313-97, Standard practice for design and construction of concrete silos and stacking tubes for storing granular materials," American Concrete Institute, Farmington Hills, MI, 1997.

[8] "AS 3774-1996, Loads on bulk solids containers," Standards Australia, Homebush, NSW, 1996.

[9] GB50077-2003, "Design Code for concrete silos" (Chinese), 2004.

[10] GB50322-2011, "Design Code for steel silos” (Chinese), 2011.

[11] Y. Zhao, Q.-S. Cao, and L. Su, "Buckling design of large circular steel silos subject to wind pressure," Thin-Walled Structures, vol. 73, pp. 337-349, 2013.

[12] J. Horabik and M. Molenda, "Mechanical properties of granular materials and their impact on load distribution in silo: A review," Scientia Agriculturae Bohemica, vol. 45, no. 4, pp. 203211, 2014

[13] C. Zeng and Y. Wang, "Compressive behavior of wheat from confined uniaxial compression tests," International Agrophysics, 2019.

[14] J. M. Boac, R. Bhadra, M. E. Casada et al., "Stored grain pack factors for wheat: Comparison of three methods to field measurements," Transactions of the ASABE, vol. 58, no. 4, pp. 1089-1101, 2015.

[15] A. Ramírez, J. Nielsen, and F. Ayuga, "Pressure measurements in steel silos with eccentric hoppers," Powder Technology, vol. 201, no. 1, pp. 7-20, 2010.

[16] M. Gao, X. Cheng, and X. Du, "Simulation of bulk density distribution of wheat in silos by finite element analysis," Journal of Stored Products Research, vol. 77, pp. 1-8, 2018.

[17] J. Durack and C. Tranberg, "A challenge for designers of steel silos," Australian Bulk Handling Review, pp. 84-89, 2010.

[18] S. A. Thompson and I. J. Ross, "Compressibility and frictional coefficients of wheat," Transaction of American Society Agricultural Engineering, vol. 26, no. 4, pp. 1171-1180, 1983.

[19] M. F. Moya, M. Guaita, P. J. Aguado, and F. Ayuga, "Mechanical properties of granular agricultural materials, part 2," Transaction of American Society Agricultural and Biological Engineering, vol. 49, no. 2, pp. 479-489, 2006.

[20] M. F. Moya, F. Ayuga, M. Guaita, and P. J. Aguado, "Mechanical properties of granular agricultural materials," Transaction of American Society Agricultural Engineering, vol. 45, no. 5, pp. 1569-1577, 2002.

[21] M. F. Moya, P. J. Aguado, and F. Ayuga, "Mechanical properties of some granular agricultural materials used in silo design," International Agrophysics, vol. 27, no. 2, pp. 181-193, 2013.

[22] Á. Ramírez, M. F. Moya, and F. Ayuga, "Determination of the mechanical properties of powdered agricultural products and sugar," Particle \& Particle Systems Characterization, vol. 26, no. 4, pp. 220-230, 2009.

[23] S. D. Liu, Z. Y. Zhou, R. P. Zou, D. Pinson, and A. B. Yu, "Flow characteristics and discharge rate of ellipsoidal particles in a flat bottom hopper," Powder Technology, vol. 253, pp. 70-79, 2014.

[24] Q. Zhang and M. G. Britton, "A micromechanics model for predicting dynamic loads during discharge in bulk solids storage structures," Canadian Biosystems Engineering, vol. 45, pp. 5.21$5.27,2003$.

[25] S. Zhang, P. Lin, C. Wang, Y. Tian, J. Wan, and L. Yang, "Investigating the influence of wall frictions on hopper flows," Granular Matter, vol. 16, no. 6, pp. 857-866, 2014. 
[26] A. Simoni and G. T. Houlsby, "The direct shear strength and dilatancy of sand-gravel mixtures," Geotechnical and Geological Engineering, vol. 24, no. 3, pp. 523-549, 2006.

[27] J.-J. Wang, J.-J. Guo, J.-P. Bai, and X. Wu, "Shear strength of sandstone-mudstone particle mixture from direct shear test," Environmental Earth Sciences, vol. 77, no. 12, article 442, 2018.

[28] S. Nam, M. Gutierrez, P. Diplas, and J. Petrie, "Determination of the shear strength of unsaturated soils using the multistage direct shear test," Engineering Geology, vol. 122, no. 3-4, pp. 272280, 2011.

[29] L. E. Vallejo and R. Mawby, "Porosity influence on the shear strength of granular material-clay mixtures," Engineering Geology, vol. 58, no. 2, pp. 125-136, 2000.

[30] J. Chen, P. C. Hagan, and S. Saydam, "Shear behaviour of a cement grout tested in the direct shear test," Construction and Building Materials, vol. 166, pp. 271-279, 2018.

[31] Trade Standard of P. R. China, "Standard method for direct shear test of coarse soil," in Specification of Soil Test, SL237-059, The Ministry of Water Resources of China, Beijing, China, 1999.

[32] S. Shibuya, T. Mitachi, and S. Tamate, "Interpretation of direct shear box testing of sands as quasi-simple shear," Géotechnique, vol. 47, no. 4, pp. 769-790, 1997.

[33] P. Guo and X. Su, "Shear strength, interparticle locking, and dilatancy of granular materials," Canadian Geotechnical Journal, vol. 44, no. 5, pp. 579-591, 2007.

[34] A. Cresswell and M. Barton, "Direct shear tests on an uncemented, and a very slightly cemented, locked sand," Quarterly Journal of Engineering Geology and Hydrogeology, vol. 36, no. 2, pp. 119-132, 2003.

[35] A. Cresswell and W. Powrie, "Triaxial tests on an unbonded locked sand," Géotechnique, vol. 54, no. 2, pp. 107-115, 2004.

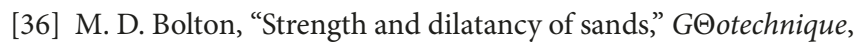
vol. 36, no. 1, pp. 65-78, 1986.

[37] M. D. Bolton, "Discussion: The strength and dilatancy of sands," Géotechnique, vol. 37, no. 2, pp. 219-226, 1987.

[38] Y. Xiao, H. Liu, X. Ding, Y. Chen, J. Jiang, and W. Zhang, "Influence of particle breakage on critical state line of rockfill material," International Journal of Geomechanics, vol. 16, no. 1, pp. 04015031-1-04015031-18, 2016. 


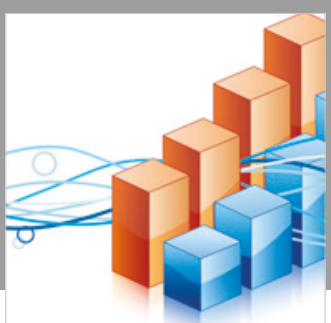

Advances in

Operations Research

\section{-n-m}
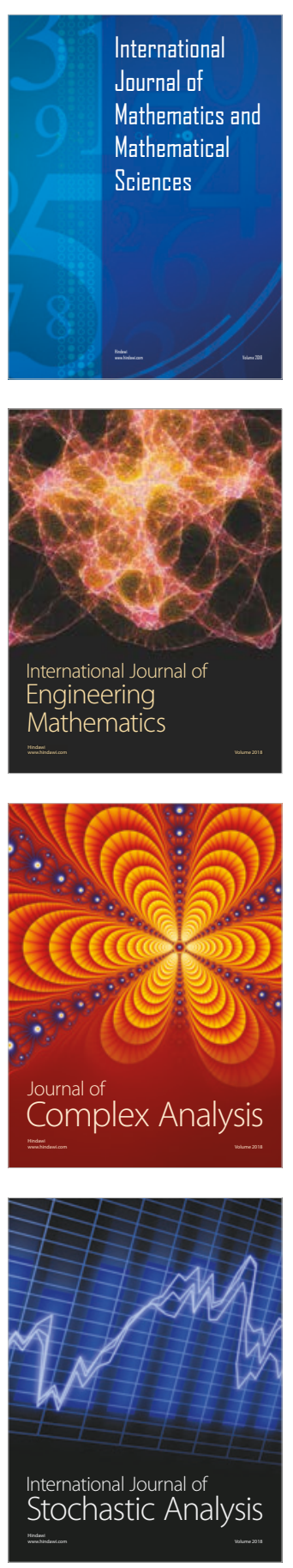
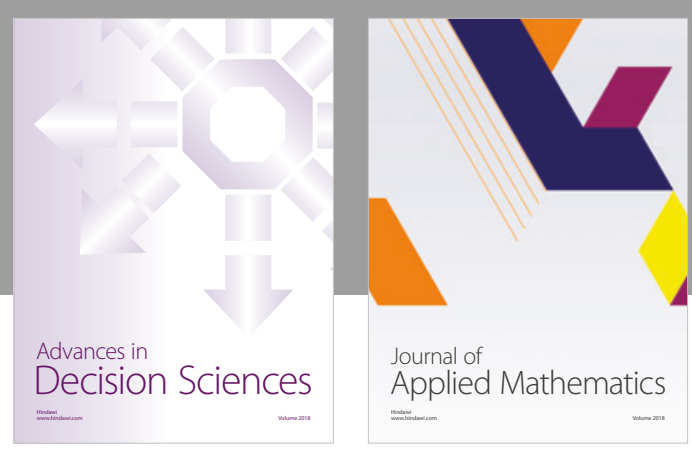

Journal of

Applied Mathematics
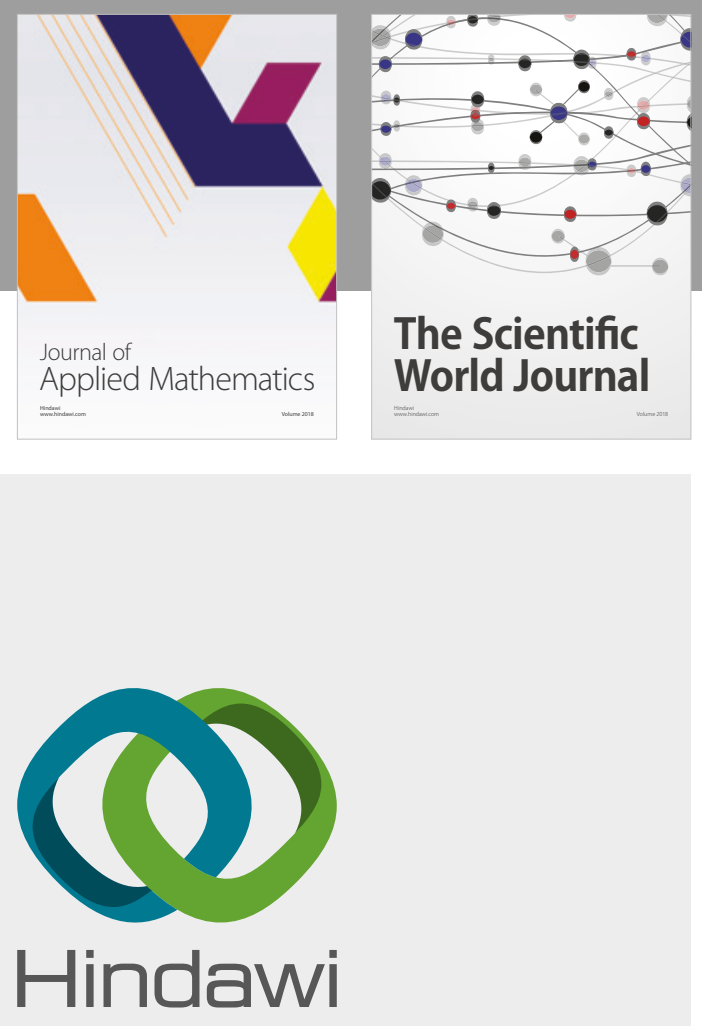

Submit your manuscripts at

www.hindawi.com

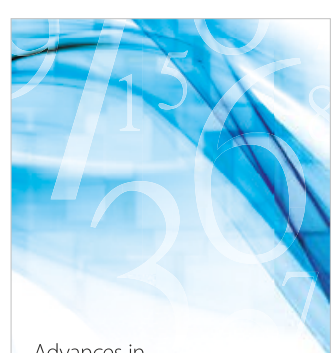

Advances in
Numerical Analysis
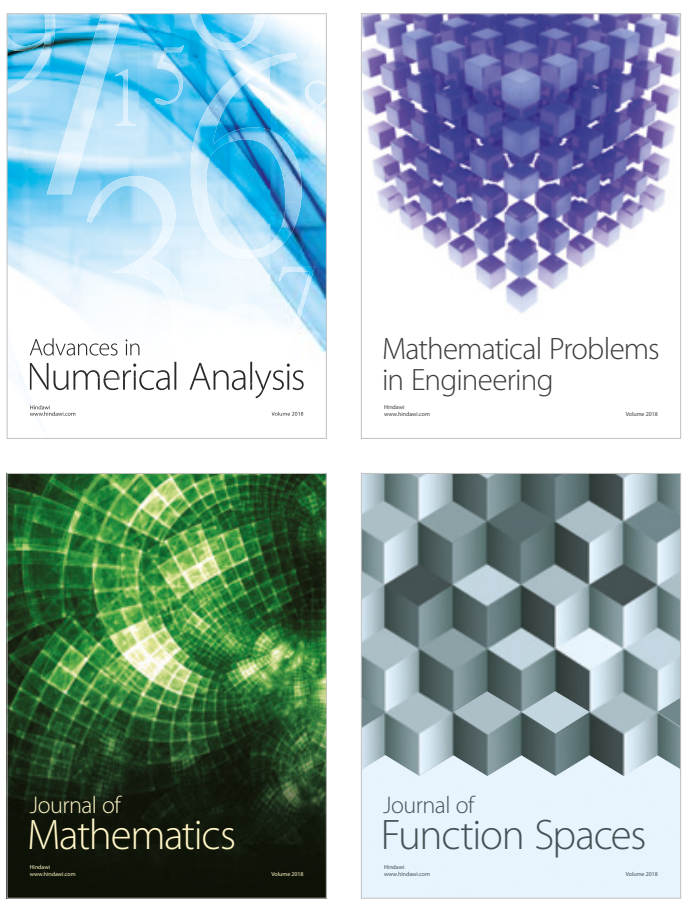

Mathematical Problems in Engineering

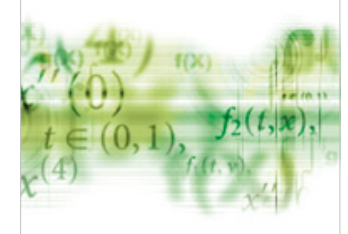

International Journal of

Differential Equations

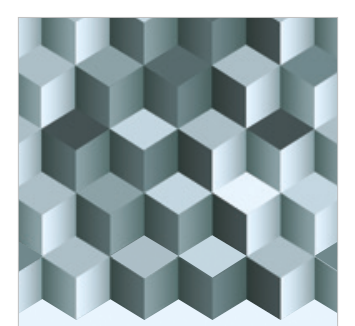

Journal of

Function Spaces
The Scientific

World Journal

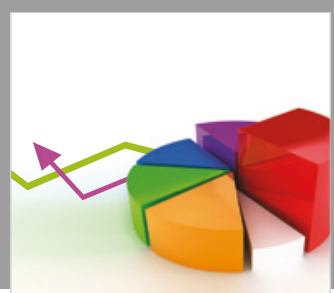

Journal of

Probability and Statistics
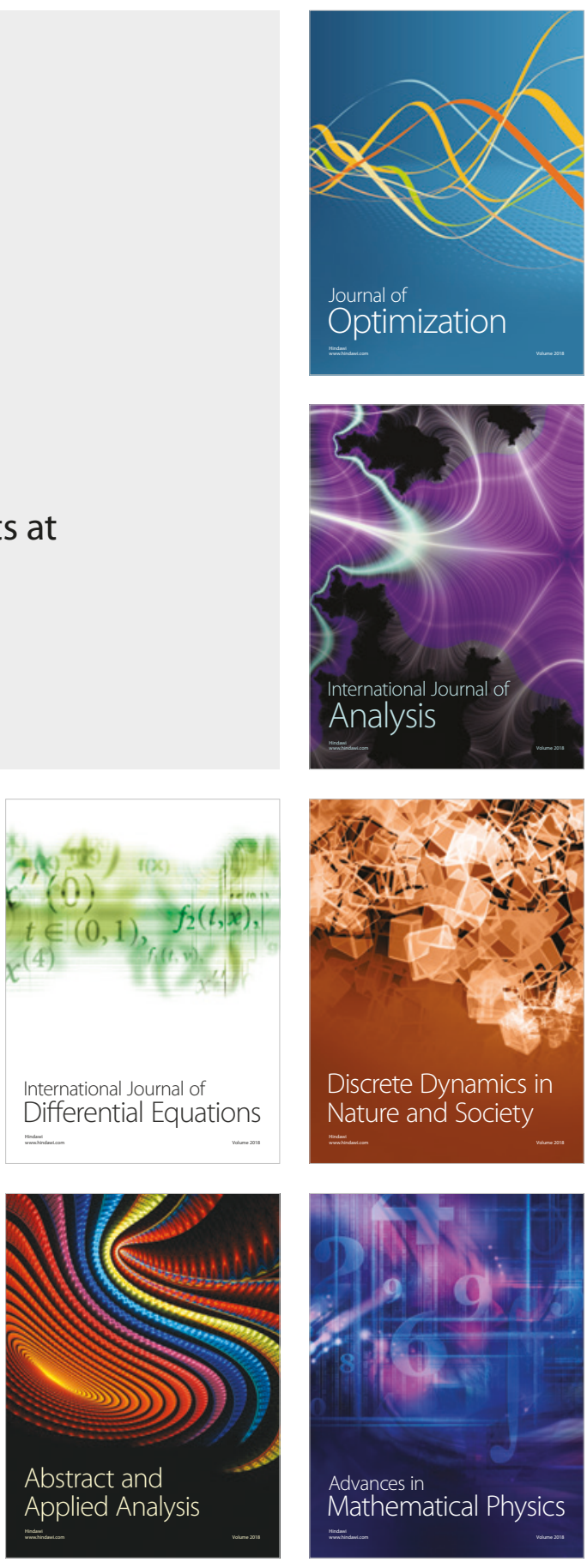